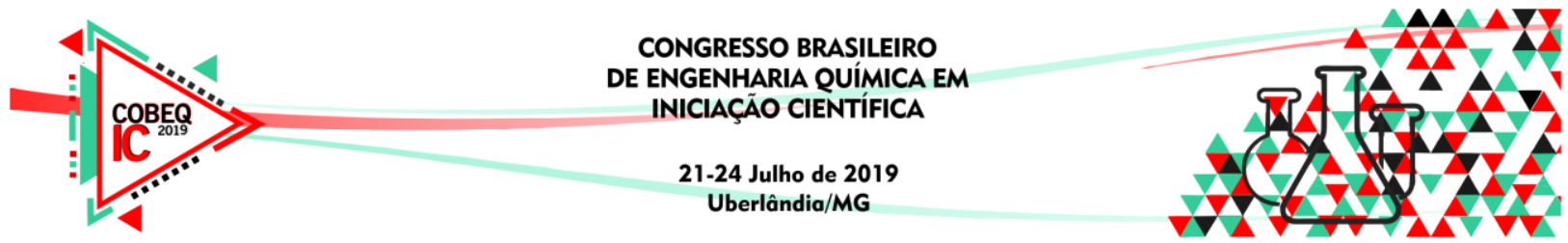

\title{
CARACTERIZAÇÃO DA POLPA RESIDUAL DE AZEITONA QUANTO AOS PARÂMETROS CÁLCIO, LÍTIO, SÓDIO E POTÁSSIO VISANDO SUA APLICAÇÃO NA AGROPECUÁRIA
}

\author{
B. F. FREITAS ${ }^{1}$, C. S. S. PEREIRA ${ }^{1,2}$, \\ W. R. CHIMATTI ${ }^{2}$, M. A. FIGUEIREDO ${ }^{3}$, D. V. B. CAMPOS ${ }^{3}$ \\ ${ }^{1}$ Universidade de Vassouras, Curso de Engenharia Química, Vassouras, Brasil, RJ \\ ${ }^{2}$ Universidade de Vassouras, Mestrado em Ciências Ambientais, Vassouras, Brasil, RJ \\ ${ }^{3}$ Embrapa Solos, Rio de Janeiro, RJ \\ E-mail para contato: brendaffernandes@yahoo.com.br
}

\begin{abstract}
RESUMO - Com a intensa industrialização, o gerenciamento de resíduos torna-se um grande entrave na região urbana. Este é um dos principais problemas enfrentados pelas indústrias no que se diz respeito à área ambiental. A agropecuária sustentável vem ganhando importância e trazendo propostas de manejo ao modelo convencional, buscando menos agressividades ao homem e a natureza. A utilização de biomassa nos solos pode auxiliar na nutrição das plantas, devido sua grande demanda orgânica. A análise dos teores de nutrientes é de suma importância, visto que, cada tipo de cultura requer suprimentos e doses específicas destes nutrientes. A caracterização quanto aos teores de potássio foi realizada em virtude de sua carência nos solos brasileiros, do sódio por ser um elemento de difícil compreensão quando aplicado às plantas, e do cálcio por ser importante no crescimento das plantas e tecidos vegetais. Diante disso, este trabalho teve como objetivo a caracterização do resíduo oriundo do processamento das azeitonas de mesa, proveniente da empresa Antares, localizada em Três Rios-RJ, quanto aos parâmetros mencionados. As análises foram realizadas com seis repetições da amostra, através da extração e determinação em fotômetro de chama demonstrando teores de $0,3 \%$ de cálcio; $0,05 \%$ de lítio; $5,01 \%$ de sódio e $0,09 \%$ de potássio.
\end{abstract}

\section{INTRODUÇÃO}

Para melhoria de vida do homem, em relação à saúde, e melhoria do meio ambiente, são exigidos produtos isentos da utilização de elementos sintéticos e defensivos químicos para preservação de qualidade aos consumidores e produtores (Araujo, 2012). Atualmente, um dos maiores desafios é perdurar o crescimento agropecuário e, em paralelo, diminuir as repercussões negativas acerca dos recursos naturais (Sambuichi et al., 2012).

De acordo com o conceito ecológico, biomassa é a porção total de matéria viva que existe em sistemas animais ou vegetais (Mamedes et al., 2010). Segundo Vieira (2012), sua caracterização é importante e pode fundar-se em análises instantâneas (teor de cinzas, umidade e voláteis), propriedades físicas (granulometria, massa específica) ou na análise 


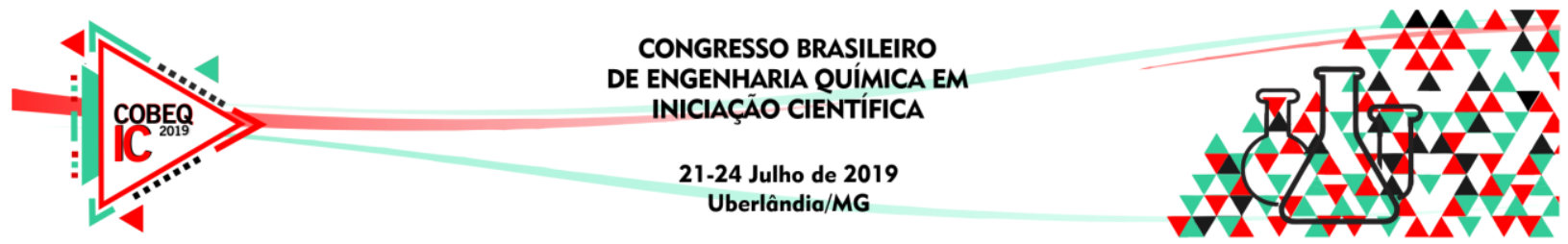

elementar, a qual verifica a presença de elementos químicos. A caracterização de biomassas é de suma importância para conhecimento tanto da origem do material utilizado, quanto das propriedades, sejam elas, químicas, biológicas ou físicas (Simões et al., 2007). Essa caracterização pode ser feita através da análise por fotometria de chama, que é uma das técnicas analíticas mais simples utilizadas para determinar íons $\mathrm{Li}^{+}, \mathrm{Na}^{+}, \mathrm{K}^{+}$e $\mathrm{Ca}^{2+}(\mathrm{Lyra}$, 2008).

Segundo Medeiros et al. (2016), no processo de produção de azeitona, há uma excessiva produção de resíduos (sólidos e líquidos), que necessitam ser tratados de forma adequada, para evitar danos ambientais com seu mau gerenciamento. A presença de quantidades elevadas de matéria orgânica e elementos minerais faz com que sua aplicação no solo, seja considerada benéfica. Em relação aos resíduos sólidos, há uma quantia de azeitona não aproveitada, em torno de 5-20 \%, visto que dependendo da sua aparência, ou seja, caso haja manchas ou defeitos, as mesmas são descartadas (Ferreira, 2015).

A síntese e a carga de compostos fenólicos, em altas concentrações de potássio nos tecidos, agem como inibidores de insetos e fungos (Silveira, 2000). Em relação ao sódio, é um elemento que provoca baixo desenvolvimento vegetal, desbalanço nutricional oriundo da alta concentração iônica e bloqueio da absorção de outros cátions pelo sódio e não menos importante, o efeito tóxico do sódio (Schossler et al., 2012).

O cálcio é importante na divisão celular das plantas, mantém a totalidade das paredes celulares, atua como ativador de enzimas e auxilia no equilíbrio cátion-ânion das células (Viecelli, 2017). O lítio é associado pelas plantas em diferentes quantidades, pois varia conforme a localização e cultura e apresenta , em pequenas doses, estimula o crescimento em culturas, mas seu papel como nutriente ainda não é preciso (Nascimento, 2014).

Diante disto, o presente trabalho tem por objetivo a caracterização da polpa de azeitona obtida no processo de descaroçamento das azeitonas de mesa quanto aos parâmetros cálcio, lítio, sódio e potássio suavizando a sua utilização na agropecuária, proporcionando o reaproveitamento de resíduos industriais favorecendo a diminuição do seu descarte ao meio ambiente.

\section{MATERIAL E MÉTODOS}

\subsection{Preparação da Amostra}

O resíduo de polpa de azeitona foi gentilmente cedido pela empresa Antares, localizada na cidade de Três Rios, no Estado do Rio de Janeiro. Os experimentos foram realizados no Laboratório de Engenharia Química da Universidade de Vassouras/RJ e no Laboratório de Tecnologia em Fertilizantes da EMBRAPA Solos/RJ. O resíduo foi submetido à secagem em estufa (QUIMIS, $\mathrm{n}^{\circ} 089$ ) com circulação à $60^{\circ} \mathrm{C}$ até apresentar peso constante, o que ocorreu após três dias. Após a secagem, o resíduo foi triturado em liquidificador doméstico, transformando-se em uma farinha. A Figura 1 ilustra a farinha obtida. 


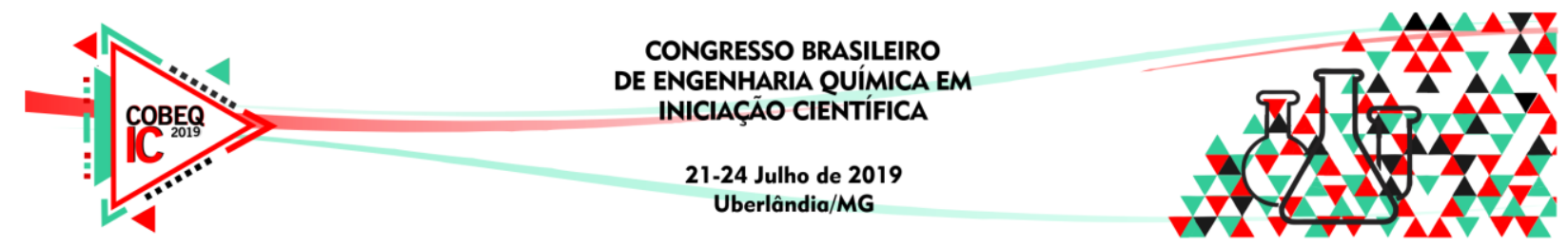

Figura 1 - Farinha obtida do resíduo de azeitona após secagem

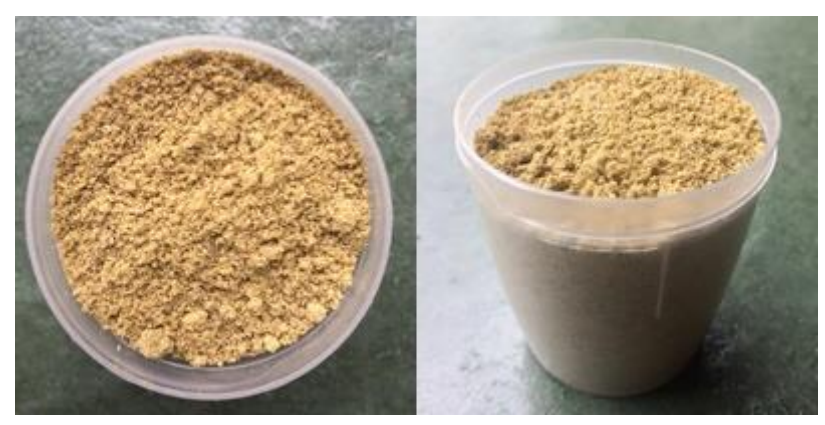

A amostra foi quarteada, separada em 6 (seis) frascos e encaminhadas ao Laboratório de Tecnologia em Fertilizantes da EMBRAPA Solos, para caracterização dos elementos cálcio $(\mathrm{Ca})$, sódio $(\mathrm{Na})$, potássio $(\mathrm{K})$ e lítio $(\mathrm{Li})$.

As análises foram realizadas de acordo com o Manual de Métodos Analíticos Oficiais para Fertilizantes e Corretivos (Brasil, 2017) e em Métodos de Análise de Tecidos Vegetais (Carmo et al., 2000). Para a leitura dos metais adaptou-se a metodologia para leitura do extrato ácido de polpa de azeitona.

\subsection{Extração ácida da amostra}

Foi pesado cerca de $1 \mathrm{~g}$ da farinha de cada uma das seis repetições, transferindo-se as amostras aos tubos de digestão, adicionando $10 \mathrm{~mL}$ de água destilada e $10 \mathrm{~mL}$ de ácido clorídrico concentrado. Em seguida, as amostras foram levadas ao bloco digestor com temperatura inicial de $180{ }^{\circ} \mathrm{C}$, por um período de duas horas. Após esse período foram adicionados $20 \mathrm{~mL}$ de ácido clorídrico e $10 \mathrm{~mL}$ de ácido nítrico concentrados, permanecendo, em aquecimento no bloco digestor em temperatura para $120^{\circ} \mathrm{C}$, até o clareamento das amostras, ilustrado na Figura 2. As amostras passaram por mudanças de tonalidade até seu clareamento. Em seguida, as amostras digeridas foram filtradas em papel de filtro de porosidade média e transferidas para balões volumétricos de $100 \mathrm{~mL}$, previamente preenchidos com água destilada, sendo posteriormente avolumados.

Figura 2 - Amostra em processo de filtração e após filtração

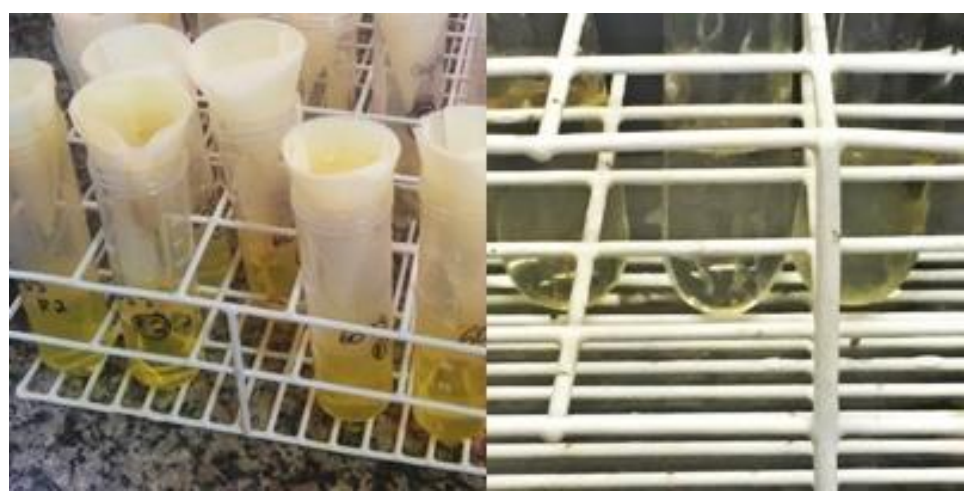




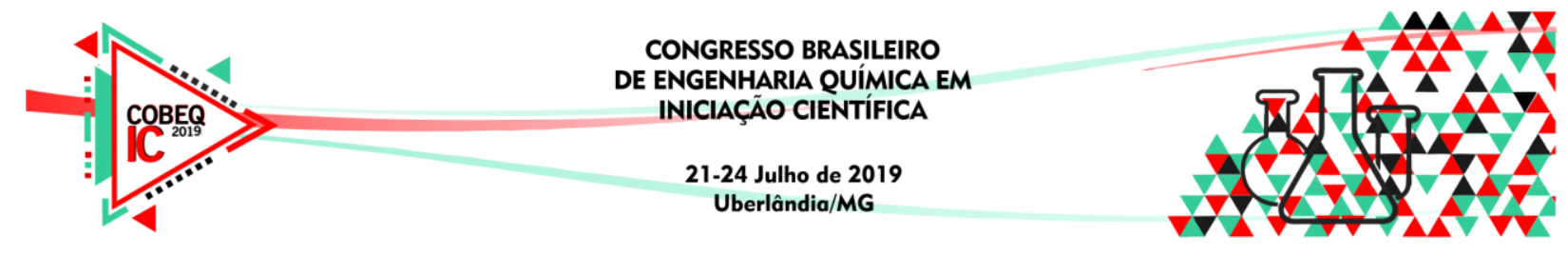

\subsection{Determinação em fotômetro de chama}

As amostras foram lidas em equipamento fotômetro de chama (DIGIMED DM 62), calibrado com dois pontos, 5 e $50 \mathrm{mg} \mathrm{L}^{-1}$ com soluções padrões de sódio, potássio, cálcio e lítio, e usando água destilada como branco. Cada leitura no fotômetro de chama durou cerca de 1 minuto. Com os resultados obtidos fez-se o cálculo das médias e desvio padrão, e os valores comparados com dados na literatura.

\section{RESULTADOS E DISCUSSÃO}

Na Tabela 1 são apresentados os resultados das análises de cálcio, lítio, sódio e potássio em \%, em fotômetro de chama.

Tabela 1 - Teores de Sódio, Potássio, Cálcio e Lítio contidos no resíduo de polpa de azeitona

\begin{tabular}{|c|c|c|c|c|}
\hline Repetições & Cálcio (\%) & Lítio (\%) & Sódio (\%) & Potássio (\%) \\
\hline 1 & 0,12 & 0,01 & 4,95 & 0,05 \\
\hline 2 & 0,67 & 0,12 & 6,9 & 0,14 \\
\hline 3 & 0,11 & 0,01 & 3,68 & 0,09 \\
\hline 4 & 0,43 & 0,07 & 6,1 & 0,11 \\
\hline 5 & 0,39 & 0,07 & 4,71 & 0,09 \\
\hline 6 & 0,09 & 0,01 & 3,72 & 0,04 \\
\hline Média & 0,30 & 0,05 & 5,01 & 0,09 \\
\hline Desvio Padrão & 0,23 & 0,05 & 1,29 & 0,04 \\
\hline
\end{tabular}

Foi encontrada uma média de 5,01\% de sódio. Segundo Inocêncio et al. (2014), o sódio pode ser considerado como um elemento que agrega benefícios, em virtude de sua presença promover maior produção de certas plantas. Porém, Bosco (2006), afirma que a presença de sódio pode ser considerada um entrave, uma vez que altas concentrações desse elemento intoxicam e dificultam a absorção da água das plantas, além de trazerem baixo rendimento na produtividade. Rodrigues et al. (2012) também afirmam que há prejuízo causado pela alta concentração de sódio sobre o metabolismo das plantas, onde a concentração de sódio no solo está aliada à redução na concentração de potássio.

Segundo Nascimento (2014), o potássio é um mineral exigido pelas plantas contribuindo com o estímulo de enzimas, crescimento das raízes, crescimento celular, condução de carboidratos, entre outros. O teor de potássio apresentou uma concentração máxima de $0,1 \%$ (Tabela 1 ), que dependendo da cultura, poderá agregar valor nutricional em sua aplicação.

O lítio obteve um teor médio de $0,05 \%$ na polpa de azeitona. Segundo Nascimento (2014), o lítio não apresenta precisão no que se diz em respeito a ser benéfico ao desenvolvimento e crescimento das plantas. Contudo, age como estimulante quando aplicado ao solo em pequenas doses. Todavia, grandes dosagens trazem toxidade às plantas, podendo 


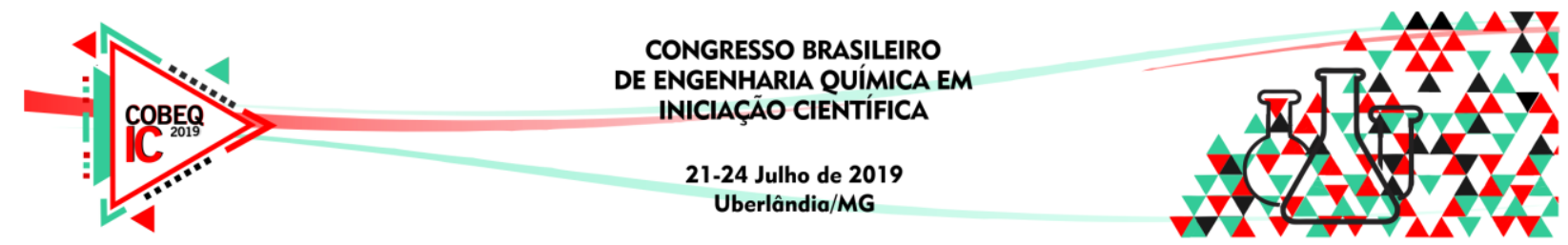

causar retardo no crescimento das mesmas. Vale salientar que, a resistência e a associação do lítio, variam em quantidades de cultura para cultura.

De acordo com Viecelli (2017), as plantas variam seus teores de cálcio no intervalo de 0,5 e $3,0 \%$, sendo o mesmo um macronutriente secundário essencial para o desenvolvimento das plantas. Os teores de cálcio encontrados na biomassa estudada apresentaram valores teores equivalentes a $0,3 \%$.

\section{CONCLUSÃO}

Foi possível a caracterização química do resíduo de polpa de azeitona após extração ácida e leitura em fotômetro de chama. Os teores de $\mathrm{Na}, \mathrm{K}, \mathrm{Ca}$ e Li foram 5,0 \%, 0,1 \%, 0,3 \% e $0,05 \%$, respectivamente. A caracterização química da biomassa em termos destes elementos, usada nos sistemas produtivos, é de grande importância, visto que, tendo o conhecimento dos teores de cada elemento, torna-se possível a realização de uma correta adubação balanceada, visando altos rendimentos na produção agropecuária. Vale salientar que são necessários maiores estudos em relação à carência de parâmetros que permitam quantificar os nutrientes estudados e da retirada de sódio presente na amostra.

\section{REFERÊNCIAS}

ARAUJO, J. S. S. Eficiência de biofertilizantes no crescimento, produção e qualidade da produção da bananeira nanica em neossolo flúvico. 2012. 63f. Dissertação de PósGraduação - Universidade Estadual da Paraíba, Campina Grande pb , ago. 2012.

BOSCO, M. R. O. Efeitos do cloreto de sódio sobre o desenvolvimento e absorção de nutrientes na cultura da berinjela. 2006. 63f. Dissertação de mestrado - Universidade Federal do Ceará, Fortaleza, ago. 2006.

BRASIL. Ministério da agricultura, pecuária e abastecimento. Manual de métodos analíticos oficiais para fertilizantes e corretivos/ Ministério da Agricultura, Pecuária e Abastecimento. Secretaria de Defesa Agropecuária - Brasília: MAPA, p.149-153,2017. 240p.

CARMO, C. A. F. S.; ARAÚJO, W. S. A.; BERnARDi, A. C. C.; SALDANHA, M. F. C. Métodos de análise de tecidos vegetais utilizados na embrapa solos. Rio de Janeiro, Embrapa Solos, p. 21-26, 2000. 41p.

FERREIRA, A.C. E. Caracterização da cadeia de valor da azeitona de mesa. 2015. 91f. Dissertação de mestre - Universidade de Lisboa, Lisboa, 2015.

INOCÊNCIO, M. F.; CARVAlHO, J. G.; NETO, A. E. F. Potássio, sódio e crescimento inicial de espécies florestais sob substituição de potássio por sódio. Rev. Árvore, Viçosa-MG, v. 38, p.113-123, 2014.

LYRA, W. S. Espectrometria de emissão em chama baseada em imagens digitais. 2008. 89f Dissertação de mestrado - Universidade Federal da Paraíba, João Pessoa, 2008. 


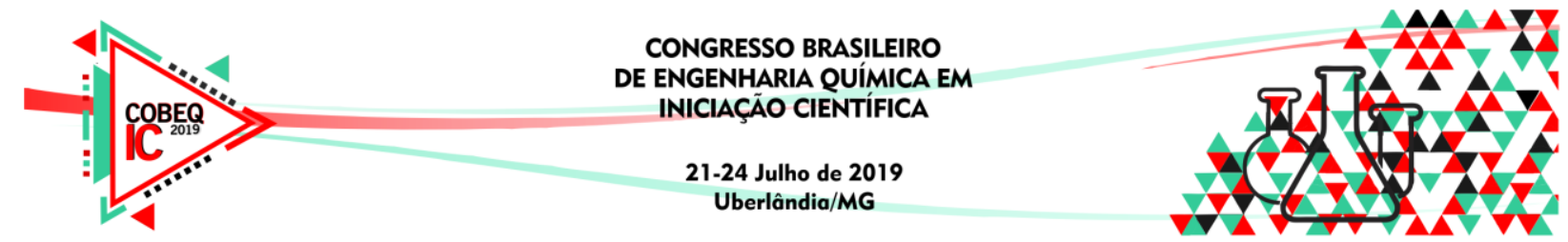

MAMEDES, J. A.; RODRIGUES, M. P. J.; VANISSANG, C. A. Biomassa no Brasil. Rev. de divulgação do Projeto Universidade Petrobras e IF Fluminense. v.1, p. 65-73, 2010.

MEDEIROS, R. M. L.; VILlA, F.; SILVA, D. F.; JÚlIO, L. R. C. V. Destinação e reaproveitamento de subprodutos da extração olivícola. Sci. agrar. parana, , v. 15, n. 2, p. 100-108, abr./jun. 2016.

NASCIMENTO, M. H. Assimilação de lítio, sódio e potássio por plantas de alface. 2014. 52f. Dissertação de mestrado - Universidade Federal do Recôncavo da Bahia - Cruz das Almas, Bahia, 2014.

ROMERO, R. R. Resposta fisiológica de plantas de Eucalyptus gandis à adubação com potássio ou sódio. 2008. 56f. Dissertação de mestrado - Universidade de São Paulo, Piracicaba, 2008.

RODRIGUES, C. R. F.; SILVEIRA, G. J. A.; SILVA, E. N.; DUTRA, A. T. B.; VIÉGAS, R. A. Transporte e distribuição de potássio atenuam os efeitos tóxicos do sódio em plantas jovens de pinhão-manso. Rev. Brasileira de Ciência do Solo, vol. 36, n. 1 - Viçosa jan-fev, 2012.

SAMBUICHI, R. H. R.; OliVEIRA, M. A. C.; SILVA, A. P. M.; GUSTAVO, L. A sustentabilidade ambiental da agropecuária brasileira: impactos, políticas públicas e desafios. Instituto de Pesquisa Econômica Aplicada - Brasília, 2012. 46p.

SIMÕES, M. L.; SILVA, W. T. L.; SAAB, S. C.; SANTOS, L. M.; NETO, L. M. Caracterização de adubos orgânicos por espectroscopia de ressonância paramagnética eletrônica. Rev. Bras. Ci. Solo, v. 31, p. 1319-1327, 2007.

SCHOSSLER, T. R.; MACHADO, D. M.; ZUFFO, A. M.; ANDRADE, F. R.; PIAUILINO, A. C. Salinidade: efeitos na fisiologia e na nutrição mineral de plantas. Enciclopédia Biosfera, Centro científico conhecer, Goiânia, v.8, n. 15; p. 1567, 2012.

SILVEIRA, R. L. A. Efeito do Potássio no crescimento, nas concentrações dos nutrientes e nas características da madeira juvenil de progênies de Eucalyptus grandis W. Hill ex Maiden cultivadas em solução nutritiva. 2000. 169f. Tese de doutorado - Estado de São Paulo, Piracicaba, 2000.

VIECELLI, C. A. Guia de Deficiências Nutricionais em Plantas. Toledo, PR: PUCPR Câmpus Toledo, 2017. 112p.

VIEIRA, A. C. Caracterização da biomassa proveniente de resíduos agrícolas. 2012.50f. Dissertação de mestrado - Universidade Estadual do Oeste do Paraná, Cascavel, PR., 2012. 